\title{
BMJ Physical exercise in southern Germany: Open a cross-sectional study of an urban population
}

\author{
Elli Rupps, ${ }^{1}$ Mark Martin Haenle, ${ }^{1}$ Juergen Steinacker, ${ }^{2}$ Richard Andrew Mason, ${ }^{3}$ \\ Suemeyra Oeztuerk, ${ }^{1}$ Ronald Steiner, ${ }^{2}$ Wolfgang Kratzer, ${ }^{1}$ the EMIL Study group*
}

To cite: Rupps E, Haenle MM, Steinacker J, et al. Physical exercise in southern Germany: a cross-sectional study of an urban population. BMJ Open 2012;2:e000713. doi:10.1136/ bmjopen-2011-000713

- Prepublication history for this paper is available online. To view this file please visit the journal online (http://dx. doi.org/10.1136/ bmjopen-2011-000713).

For author footnote see end of the article.

Received 2 December 2011 Accepted 15 February 2012

This final article is available for use under the terms of the Creative Commons Attribution Non-Commercial 2.0 Licence; see http://bmjopen.bmj.com

For numbered affiliations see end of article.

Correspondence to Professor Wolfgang Kratzer; wolfgang.kratzer@ uniklinik-ulm.de

\section{ABSTRACT}

Objectives: The aim of this study was to investigate the degree of physical exercise and self-assessment of physical fitness (PF) and their relationship to healthand behaviour-specific factors in a randomly selected sample of an urban population in southern Germany.

Design: Cross-sectional study.

Setting: In the southern German city of Leutkirch. Participants: 2187 subjects randomly selected from the registry of inhabitants. Of the selected group, aged 18-65 years, $52.1 \%$ were women and $47.9 \%$ men.

\section{Primary and secondary outcome}

measures: Participants were asked how many hours per week they spent on physical exercise and sports. They were also asked to rate their own performance and/or PF.

Results: Overall, $38.9 \%$ of the participants reported no physical exercise. Men reported a higher level of physical exercise than did women. Less exercise was reported by subjects with diabetes, high body mass index and waist-to-hip ratio and by those who were underweight. Alcohol consumption, smoker status and higher educational level showed a positive association with physical exercise. A negative trend with respect to moderate physical exercise was observed for those with metabolic syndrome, diabetes, hypertension and hepatic steatosis, but this was statistically significant only for subjects with diabetes. In both men and women, there was a relationship between selfassessed 'good' PF and high physical exercise.

Conclusions: The data show that a large proportion of the study population is not physically active; specific risk groups (overweight subjects, older subjects, smokers or subjects with low educational level) are even less active. The data suggest that there is a great potential for measures promoting physical exercise in these groups.

\section{INTRODUCTION}

Physical inactivity is an important behavioural risk factor that is associated with many negative health consequences. The health benefit of regular physical activity relates to an improved quality of life and reduces the risk of a variety of disorders, including

\section{ARTICLE SUMMARY}

\section{Article focus}

- To investigate the degree of physical exercise and self-assessment of PF and relationship to health- and behaviour-specific factors in a randomly selected sample of an urban population in southern Germany.

Key messages

- Individuals with high educational level are more likely to be physically active.

- Physical exercise is more prevalent in men then in women and is inversely associated with body mass index.

- There is need of promoting physical exercise particularly for special risk groups.

Strengths and limitations of this study

- The strengths of this study include the randomly selected study population with its relatively large size and response rate.

- Because of its cross-sectional design, our present study does not identify causal relationships between physical exercise and other factors surveyed.

- Physical exercise was surveyed on the basis of subjects' self-reports assessed in a standardised interview and not measured quantitatively.

overweight, cardiovascular diseases, diabetes mellitus type 2, stroke and osteoporosis. There is also reduction in both cardiovascular and overall mortality. ${ }^{1-5}$ Although the benefits of regular physical activity are widely known, physical exercise remains low in Germany as in most industrialised nations. ${ }^{6-9}$ There is a known association of physical exercise with alcohol consumption, nonsmoker status and healthy diet. ${ }^{10-13}$ These associations, which also point to behaviourcorrelated health risks, are important for the planning and implementation of measures promoting health.

Objective of the present study was to assess the level of physical exercise in an urban population and to identify inactive subgroups 
for future preventive health strategies. A randomly selected population sample was examined to determine the relationship between body mass index (BMI), waistto-hip ratio, alcohol and tobacco consumption, sonographically assessed hepatic steatosis, socio-demographic and behaviour-specific factors, as well as age- and gender-specific differences and physical exercise.

\section{METHODS}

Subjects

In 2002, we conducted a population-based crosssectional health survey in the southern German city of Leutkirch (EMIL Study). ${ }^{14}$ A total of 4000 of 12475 persons of an urban population were randomly selected from the registry of inhabitants and invited to participate in the study. Of those invited, 2445 persons aged 10-65 years participated in the study (participation rate: $62.8 \%$ ). Following exclusion of minors (age $<18$ years; $\mathrm{n}=258$ ) and those not providing responses regarding the exercise activities $(n=17)$, a total 2173 subjects aged 18-65 years were included in the present analysis.

A more detailed description of subject recruitment has been published elsewhere. ${ }^{14}$

Subjects participated in a structured interview (questionnaire) and underwent anthropometric measurements, blood sample collection and an ultrasound examination. Each investigation was conducted by a trained interviewer. The questionnaire included personal data (eg, date of birth, gender, education, medical history), health behaviour (eg, exercise) and other risk factors for disease (eg, smoking). In order to validate the results, multiple cross-checked questions on the same topic were addressed to the participants. The interview was partially based on validated instruments from other studies (eg, alcohol questions from the MONICA Study). ${ }^{15}$ The study met the international guidelines of the 1996 Helsinki Declaration and was approved by the Research Ethics Committee of the Baden-Württemberg State Medical Council (Landesärztekammer Baden-Württemberg).

\section{Assessment of physical exercise}

Physical exercise was assessed using questions modified from the MONICA/KORA study and from the questionnaire of Voorips et $a l^{3}{ }^{9}{ }^{16}$ Participants were asked how many hours per week they spent on physical exercise and sports $(0-2,2-4,4-10,>10 \mathrm{~h})$. Those who did not report physical exercise were defined as physically inactive. Three groups were formed for multivariate analysis: subjects with 'high' (more than $4 \mathrm{~h}$ /week), 'moderate' (0-4 h/week) and 'no' physical exercise.

Subjects were also asked to rate their own performance and/or physical fitness (PF) on a scale of 0 (not at all) to 10 (very fit) using a Visual Analogue Scale provided by the interviewer. Based on these responses, subjects' PF was classified as 'good' (7-10), 'moderate' (4-6) and 'poor' $(0-3)$.
Anthropometry

Based on WHO recommendations, ${ }^{17}$ we determined subjects' height, body weight, hip and waist circumference. Underweight, normal weight, overweight and obesity were defined as follows: underweight $=\mathrm{BMI}$ $<18.5 \mathrm{~kg} / \mathrm{m}^{2}$; normal weight $=$ BMI 18.5 to $<25 \mathrm{~kg} / \mathrm{m}^{2}$; overweight $=$ BMI 25 to $<30 \mathrm{~kg} / \mathrm{m}^{2}$; obesity, grade I = BMI 30 to $<35 \mathrm{~kg} / \mathrm{m}^{2}$; obesity, grade II $=$ BMI 35 to $<40 \mathrm{~kg} / \mathrm{m}^{2}$; obesity, grade III $=\mathrm{BMI}>40 \mathrm{~kg} / \mathrm{m}^{2}$.

\section{Laboratory measurements}

Laboratory testing included analytical clinical chemistry for serum or plasma levels of triglycerides, total cholesterol and high-density lipoprotein (HDL) cholesterol (Dimension XL; Dade Behring Inc., Newark, Delaware, USA). As far as possible, tests were conducted according to the guidelines of the IFCC (International Federation of Clinical Chemistry and Laboratory Medicine). Lowdensity lipoprotein (LDL) cholesterol was calculated using the Friedewald formula. ${ }^{18}$ Following reference ranges were used in assessing subjects' laboratory findings: total cholesterol $<5.2 \mathrm{mmol} / 1$, triglycerides $<2.3 \mathrm{mmol} / \mathrm{l}$, LDL cholesterol $<4.1 \mathrm{mmol} / 1$ and HDL cholesterol $>1.0 \mathrm{mmol} / 1$ (men) and $>1.2 \mathrm{mmol} / 1$ (women).

\section{Metabolic syndrome}

For purposes of the present study, metabolic syndrome was diagnosed when subjects met at least three of the following five criteria modified from ATP III: obesity with a BMI $>30 \mathrm{~kg} / \mathrm{m}^{2}$, serum triglycerides $>1.7 \mathrm{mmol} / \mathrm{l}$, HDL $<1.0 \mathrm{mmol} / 1$ (men) or $<1.2 \mathrm{mmol} / 1$ (women), history of arterial hypertension, random blood glucose $>8.9 \mathrm{mmol} / \mathrm{l}$ and/or history of diabetes mellitus. ${ }^{19}$ Data on hypertension and diabetes were assessed from subjects' past medical history.

\section{Ultrasonography}

Ultrasonographic examination of the liver was performed using four identical ATL/Philips HDI 5000 ultrasound scanners (ATL Ultrasound; Philips Medical Systems, Bothell, Washington, USA) with identical settings and a $2-5 \mathrm{MHz}$ probe. Assessment of hepatic steatosis was performed using criteria established by Saverymuttu et al. $^{20}$

\section{Statistics}

Absolute and relative frequencies were calculated for qualitative factors in the descriptive statistical analysis, while for quantitative factors, mean and SD, as well as median, minimum and maximum, were calculated.

The multivariate analysis was performed using a logistic regression model. Association of moderate to high physical exercise with socio-demographic, behaviour-specific and health-relevant factors as well as with subjects' PF was determined and evaluated using ORs and $95 \%$ CI derived from the logistic regression analysis. In order to make representative statements, data were adjusted for gender, age, BMI, educational level, tobacco and alcohol consumption. 
The statistical evaluation was performed using the SAS V.9.2 statistical software program.

\section{RESULTS}

Overall, $38.9 \%$ of subjects reported no physical exercise. High physical exercise was significantly more prevalent among men compared with women (OR 2.05, 95\% CI 1.46 to 2.87 ) and had a negative association with age (table 1). Subjects with high BMI and those who were underweight reported less physical exercise than did subjects of normal body weight. For waist-to-hip ratio, there was a negative association with moderate (OR 0.73 , $95 \%$ CI 0.62 to 0.87 ) and high (OR $0.64,95 \%$ CI 0.48 to 0.87) physical exercise.

A strong association was identified between physical exercise and level of educational achievement. Participants with GCSE equivalent (Realschulabschluss) and A-level equivalent (Abitur) were significantly more active than those with CSE equivalent (Hauptschulabschluss; OR 1.94 and 2.74). Smokers were significantly less physically active than were non-smokers. Alcohol consumption, however, showed a positive association with physical exercise, with the strongest association in the group with daily alcohol consumption of 21-40 g/day (table 2).

A negative trend with respect to moderate physical exercise was observed for those with metabolic syndrome, elevated LDL or triglyceride values, lowered HDL values, diabetes, hypertension and hepatic steatosis, but this was only significant for subjects with diabetes (OR 0.45 , 95\% CI 0.24 to 0.86 ; table 3 ).

The distribution of subjects' self-assessment of PF was quite uniform across all age groups (figure 1). Approximately $50 \%$ of women and $58 \%$ of men estimated their $\mathrm{PF}$ as 'good' and a further $44 \%$ of women and $37 \%$ of men as 'moderate'. Only $7 \%$ of women and $5 \%$ of men rated their $\mathrm{PF}$ as 'poor'. In order to determine the influence of physical exercise on the subjective assessment of PF, the group of women and men with selfassessed 'good' PF was broken down according to the degree of their physical exercise, and logistic regression, adjusted for age, was performed. The OR of high physical exercise level (more than $4 \mathrm{~h} /$ week) associated with 'good' PF was 2.6 for men and 3.2 for women (figure 2, table 4).

\section{DISCUSSION}

The purpose of this study was to assess the prevalence of physical exercise in an urban population in southern Germany and explore the specific risk groups for possible intervention programmes.

The EMIL Study is a population-based cross-sectional study of an urban population in southern Germany. The rate of participation was $62.8 \% \quad(\mathrm{n}=2445)$, which is comparable to other cross-sectional studies. ${ }^{21} 22$

The prevalence of inactivity was approximately $39 \%$ with significant differences across subgroups. The present study shows that high physical exercise is more prevalent in men than in women, independent of age, BMI, educational level, tobacco or alcohol consumption. Although the results are not directly comparable to other studies using different questionnaires, the majority of studies report a higher degree of physical activity among men. ${ }^{6} 122324$ Our study identified age differences in physical exercise. The prevalence of inactivity was the highest in the 51-65-year-old age group. Although most studies in Europe and the USA ${ }^{11} 2123$ report that physical activity declines with age, some studies from Asia show a positive association between physical activity and increasing age. ${ }^{25} 26$ This is possibly a result of increased leisure-time physical activity participation after retirement. ${ }^{26}$ Older people are at a higher risk for disability and reduction in cardiopulmonary capacity: hence, intervention programmes should focus more on physical activity opportunities for the older

Table 1 Association of PE with anthropometric factors

\begin{tabular}{|c|c|c|c|c|c|}
\hline & \multicolumn{3}{|c|}{ Exercise, $\mathbf{N}(\%)$} & \multicolumn{2}{|l|}{ OR (95\% Cl) $\dagger$} \\
\hline & No & Moderate & High & Moderate vs no PE & High vs no PE \\
\hline \multicolumn{6}{|l|}{ Gender } \\
\hline Female & $446(41)$ & $561(51)$ & $93(9)$ & References & References \\
\hline Male & $378(38)$ & $467(47)$ & 155 (16) & $0.94(0.76$ to 1.16$)$ & $2.05(1.46 \text { to } 2.87)^{*}$ \\
\hline \multicolumn{6}{|l|}{ Age } \\
\hline $18-30$ & $134(34)$ & $182(46)$ & $81(20)$ & References & References \\
\hline $31-40$ & 217 (39) & $283(51)$ & $53(10)$ & $1.00(0.74$ to 1.36$)$ & $0.44(0.28 \text { to } 0.70)^{*}$ \\
\hline $41-50$ & 180 (37) & $257(53)$ & $50(10)$ & $1.11(0.81$ to 1.53$)$ & $0.59(0.37 \text { to } 0.95)^{*}$ \\
\hline $51-65$ & $293(44)$ & $306(46)$ & $64(10)$ & $0.96(0.70$ to 1.31$)$ & $0.54(0.34 \text { to } 0.86)^{\star}$ \\
\hline \multicolumn{6}{|l|}{ BMI $\left(\mathrm{kg} / \mathrm{m}^{2}\right)$} \\
\hline Underweight $(<18.5)$ & $23(44)$ & $27(52)$ & $2(4)$ & $0.78(0.43$ to 1.42$)$ & $0.19(0.04 \text { to } 0.89)^{*}$ \\
\hline Normal $(18.5<25)$ & 325 (33) & $520(52)$ & $147(15)$ & References & References \\
\hline Overweight $(25<30)$ & $278(41)$ & $332(49)$ & $72(11)$ & 0.81 (0.64 to 1.02$)$ & $0.57(0.40 \text { to } 0.82)^{*}$ \\
\hline Adipositas $(\geq 30)$ & $198(53)$ & $149(40)$ & $27(7)$ & $0.55(0.42 \text { to } 0.72)^{*}$ & $0.34(0.21 \text { to } 0.55)^{*}$ \\
\hline
\end{tabular}


Table 2 Association of PE with behaviour risk factors

\begin{tabular}{|c|c|c|c|c|c|}
\hline & \multicolumn{3}{|c|}{ Exercise, N (\%) } & \multicolumn{2}{|l|}{ OR $(95 \% \mathrm{Cl}) \dagger$} \\
\hline & No & Moderate & High & Moderate vs no PE & High vs no PE \\
\hline \multicolumn{6}{|c|}{ Educational achievement } \\
\hline No education & $39(81)$ & $7(15)$ & $2(4)$ & $0.27(0.12 \text { to } 0.62)^{\star}$ & $0.36(0.08$ to 1.57$)$ \\
\hline CSE equivalent & $458(49)$ & $396(42)$ & $81(9)$ & References & References \\
\hline GCSE equivalent & 203 (33) & $338(54)$ & $80(13)$ & $1.78(1.41 \text { to } 2.25)^{*}$ & $1.94(1.32 \text { to } 2.85)^{\star}$ \\
\hline A-levels equivalent & $118(26)$ & $270(59)$ & $73(16)$ & $2.35(1.80 \text { to } 3.06)^{\star}$ & $2.74(1.83 \text { to } 4.09)^{*}$ \\
\hline \multicolumn{6}{|l|}{ Smoking } \\
\hline Current smoker & $299(47)$ & $275(43)$ & $60(10)$ & $0.65(0.51 \text { to } 0.82)^{*}$ & $0.45(0.31 \text { to } 0.66)^{\star}$ \\
\hline Ex-smoker & $174(35)$ & $264(53)$ & $65(13)$ & $1.11(0.86$ to 1.43$)$ & 0.99 (0.67 to 1.46$)$ \\
\hline Non-smoker & 351 (37) & $489(51)$ & $123(13)$ & References & References \\
\hline \multicolumn{6}{|l|}{ Alcohol consumption } \\
\hline Ex-consumer & $41(47)$ & $36(41)$ & $10(12)$ & $1.19(0.72$ to 1.97$)$ & $1.32(0.60$ to 2.93$)$ \\
\hline No consumption & $329(47)$ & $296(43)$ & $71(10)$ & References & References \\
\hline $0-20 \mathrm{~g} /$ day & 317 (35) & $469(52)$ & $110(12)$ & $1.47(1.18 \text { to } 1.85)^{*}$ & 1.40 (0.96 to 2.04$)$ \\
\hline $21-40 \mathrm{~g} /$ day & $82(30)$ & $153(56)$ & 39 (14) & $2.00(1.43 \text { to } 2.80)^{*}$ & $1.99(1.18 \text { to } 3.33)^{*}$ \\
\hline$>40 \mathrm{~g} /$ day & $55(37)$ & $74(50)$ & $18(12)$ & $1.69(1.11 \text { to } 2.58)^{*}$ & $1.40(0.72$ to 2.72$)$ \\
\hline
\end{tabular}

people. $^{27}$ Studies of physical activity and leisure-time physical activity in Bavaria confirm the findings of the present study and show that increased physical activity, especially in non-obese women, is associated with a decreased rate of type 2 diabetes mellitus. ${ }^{3} 6$
There were also differences in physical exercise in relation to subjects' educational level. By far, the highest degree of physical inactivity was reported in women $(93 \%)$ and men $(63 \%)$ who had not completed formal education and declines with increasing educational

Table 3 Association of PE with other risk factors

\begin{tabular}{|c|c|c|c|c|c|}
\hline & \multicolumn{3}{|c|}{ Exercise, N (\%) } & \multicolumn{2}{|l|}{ OR $(95 \% \mathrm{CI}) \dagger$} \\
\hline & No & Moderate & High & Moderate vs no PE & High vs no PE \\
\hline \multicolumn{6}{|c|}{ Metabolic syndrome } \\
\hline No & $723(38)$ & $955(50)$ & $229(12)$ & References & References \\
\hline Yes & $74(56)$ & $45(34)$ & $13(10)$ & $0.72(0.46$ to 1.13$)$ & $1.32(0.61$ to 2.83$)$ \\
\hline \multicolumn{6}{|c|}{ Steatosis hepatis } \\
\hline No & $534(36)$ & $757(51)$ & $191(13)$ & Reference & References \\
\hline Grade I & $98(43)$ & $115(50)$ & $17(7)$ & $0.99(0.72$ to 1.38$)$ & $0.76(0.41$ to 1.39$)$ \\
\hline Grade II/III & $182(49)$ & $152(41)$ & $40(11)$ & $0.76(0.55$ to 1.04$)$ & 0.88 (0.53 to 1.45$)$ \\
\hline \multicolumn{6}{|l|}{ Diabetes } \\
\hline No & 789 (39) & $1009(50)$ & $239(12)$ & References & References \\
\hline Yes & $33(57)$ & $16(28)$ & 9 (16) & $0.45(0.24 \text { to } 0.86)^{*}$ & $1.11(0.48$ to 2.60$)$ \\
\hline \multicolumn{6}{|l|}{ Hypertension } \\
\hline No & $654(37)$ & $878(50)$ & $215(12)$ & References & References \\
\hline Yes & $159(49)$ & $135(41)$ & 32 (10) & $0.79(0.59$ to 1.05$)$ & 0.99 (0.61 to 1.62$)$ \\
\hline \multicolumn{6}{|l|}{ HDL } \\
\hline Normal & $656(38)$ & $864(50)$ & $210(12)$ & References & References \\
\hline Reduced & $140(48)$ & $121(41)$ & $31(11)$ & $0.88(0.66$ to 1.17$)$ & $0.92(0.57$ to 1.48$)$ \\
\hline \multicolumn{6}{|l|}{ LDL } \\
\hline Normal & $561(39)$ & $689(48)$ & $173(12)$ & References & References \\
\hline Elevated & 137 (42) & $157(48)$ & $31(10)$ & $1.01(0.77$ to 1.33$)$ & $0.76(0.48$ to 1.21$)$ \\
\hline \multicolumn{6}{|l|}{ Triglyceride } \\
\hline Normal & $500(38)$ & $663(50)$ & $156(12)$ & References & References \\
\hline Elevated & 264 (45) & $257(44)$ & 69 (12) & $0.83(0.66$ to 1.05$)$ & $0.96(0.66$ to 1.41$)$ \\
\hline \multicolumn{6}{|l|}{ Cholesterin } \\
\hline Normal & $306(39)$ & $369(47)$ & $105(14)$ & References & References \\
\hline Elevated & $511(39)$ & $644(50)$ & $141(11)$ & $1.11(0.90$ to 1.38$)$ & $1.04(0.74$ to 1.47$)$ \\
\hline
\end{tabular}




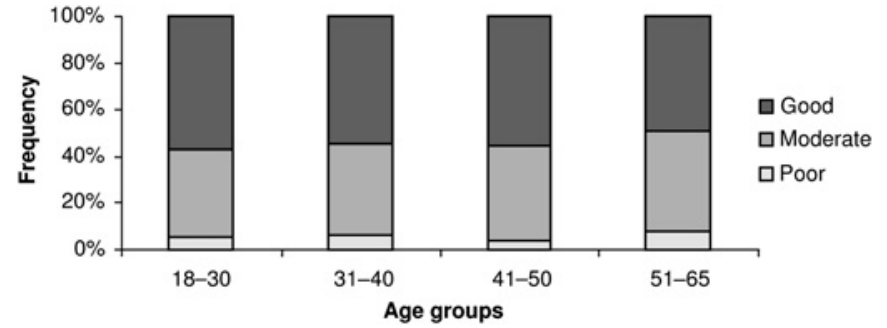

Figure 1 Self-assessed physical fitness according to age groups.

level. In the multivariate analysis, this association was shown to be statistically significant for moderate and high physical exercise. Several studies have shown a strong negative relationship between prevalence of physical activity and educational level. ${ }^{3} 2528$ Among the possible reasons that have been discussed for these observations are health-related attitudes that vary with educational level, as well as differences in health knowledge and forms of social integration.

Our findings agree with a majority of studies indicating an inverse association between physical activity and increasing BMI or waist circumference. Interestingly, underweight women, but not underweight men, were also significantly less physically active. ${ }^{29} 30$

The results of the present study are in accordance with previous studies, which have shown that physical activity is associated with a reduced risk of type 2 diabetes. ${ }^{3}$ 31-33 However, we did not show an association between metabolic syndrome and physical exercise. Halldin $e t a l^{34}$ reported a strong negative association between physical exercise and metabolic syndrome in 60-year-olds. Other studies from Finland, Great Britain and Mexico using self-reports of physical activity or objective measurements confirm these findings. ${ }^{35-37}$ Unlike results published by Hsieh et $a l^{38}$ our data did not show a significant difference in the prevalence of hepatic steatosis between subjects reporting physical exercise and those who are physically inactive.

In agreement with other studies, our findings showed that male and female smokers were significantly less physically active than were non-smokers. ${ }^{3} 39$ Participants reporting consumption of moderate amounts of alcohol were more physically active than those reporting no

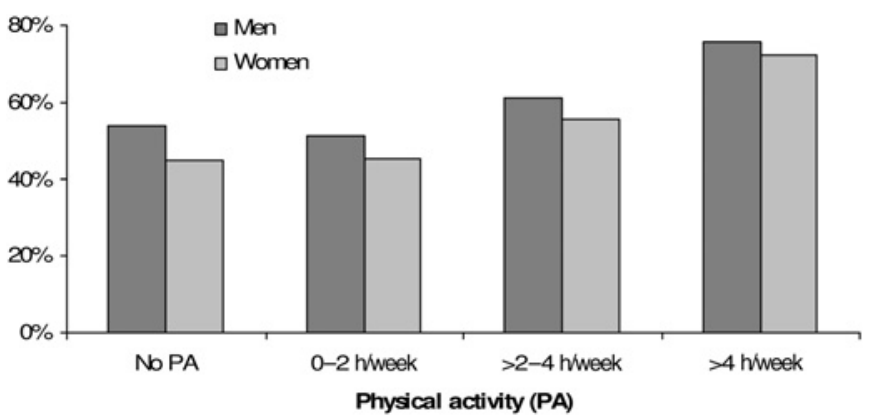

Figure 2 Physical activity in women and men with selfassessed 'good' physical fitness.
Table 4 Association of physical exercise with selfassessed 'good' physical fitness

$\begin{array}{ll}\text { Men } & \text { Women } \\ \text { OR† }(95 \% \mathrm{Cl}) & \text { OR† }(95 \% \mathrm{Cl})\end{array}$

Physical exercise

No References References

0-4 h/week $1.06(0.81$ to 1.38$) \quad 1.17(0.91$ to 1.50$)$

$>4 \mathrm{~h} /$ week $2.57(1.69 \text { to } 3.90)^{\star} \quad 3.21(1.99 \text { to } 5.20)^{\star}$

${ }^{*} \mathrm{p}<0.05$

†Adjusted for age.

alcohol consumption. A similar observation was reported for the MONICA/KORA Study in which persons with moderate alcohol consumption patterns tended towards a higher activity level than did non-drinkers. ${ }^{3}$ Associations with smoking and alcohol consumption may provide evidence for the accumulation of behaviourcorrelated health risks. This makes them relevant for planning and implementation of measures for promoting health.

Our study showed significant differences between selfassessed $\mathrm{PF}$ in active and inactive persons. Men and women with higher levels of physical exercise estimated their PF more frequently as 'good' than did those who reported no physical exercise. Although other studies queried subjects' subjective general health status rather than PF, findings were very similar with regard to physical activity. Becker et $a t^{40}$ showed that persons with poor subjective assessment of general health were underrepresented in the physically active group. Pan et at reinforced this result when considering both sexes together. Participants who reported poor general health status were less likely to have sufficient physical activity than did those who had a good general health status. If we compare our self-assessed PF with subjective general health ratings reported by Lampert et $a l^{7}{ }^{7}$ we find comparable self-assessments and a similar survey method of physical exercise, despite differences in definitions. The findings also showed a relationship between physical activity and self-assessed 'very good' general health and significant differences between physically active and inactive subjects. Unlike our data, that survey included only persons who denied any chronic disease or physical disorder; therefore, it is more probable to associate a health-promoting effect with physical activity.

Based on the study design, the present study shows certain limitations and weaknesses. Because of its crosssectional design, our study does not identify causal relationships between physical exercise and other factors surveyed. The results obtained in this study did not include work-related, household and commuting activities, which are not routinely included in physical exercise measurements but are also important contributors to total physical activity and could perhaps diminish the differences in physical exercise levels between genders. Physical exercise was surveyed on the basis of subjects' self-reports assessed in a standardised interview and not 
measured quantitatively. Self-reported data may result in overestimation, especially in the assessment of physical exercise. ${ }^{6}$ Objective methods such as accelerometers, pedometers or heart rate monitoring are more precise than subjective assessment. ${ }^{42}{ }^{43}$ However, performing such quantitative measurements in large populationbased studies is difficult and cost-intensive. For this reason, most epidemiologists have opted to use questionnaires for this purpose.

The strengths of this study include the randomly selected study population with its relatively large size and response rate. The survey of physical exercise, behaviour patterns and medical history together with laboratory studies and other examinations were performed by specially trained personnel.

In conclusion, the results of the present study show that a large proportion of the population is not physically active. Thus, the potential benefit of measures promoting physical exercise is very high. Special risk groups (older subjects, overweight persons, smokers, persons with low educational achievement) with known low levels of physical exercise have a particularly large potential for measures promoting physical exercise.

\section{Author affiliations \\ ${ }^{1}$ Department of Internal Medicine I, University Hospital UIm, UIm, Germany ${ }^{2}$ Department of Internal Medicine II, Division of Sports and Rehabilitation, University Hospital UIm, UIm, Germany \\ ${ }^{3}$ Department of Veterans Affairs Medical Center, Louis Stokes Cleveland, Brecksville, Ohio, USA \\ Author footnote \\ * Members of the EMIL Study group (Echinococcus Multilocularis and Internal Diseases in Leutkirch): Adler G, Armsen A, Banzhaf H-M, Bauerdick M, Bertling U, Boehm B O, Brandner B O, Brockmann S O, Deckert M, Dingler C, Eggink S, Fuchs M, Gaus W, Goussis H, Gruenert A, Haenle M M, Hampl W, Haug C, Hay B, Huetter M-L, Imhof A, Kern P, Kimmig P, Kirch A, Klass D, Koenig W, Kratzer W, Kron M, Manfras B, Meitinger K, Mertens T, Oehme R, Pfaff G, Piechotowski I, Reuter S, Romig T, von Schmiesing A F A, Steinbach G, Tourbier M, Voegtle A, Walcher T, Wolff S.}

Acknowledgements The study was initiated by the government of BadenWürttemberg, Germany.

Contributors Substantial contributions to conception and design, acquisition of data or analysis and interpretation of data: ER, MMH, RS, SO, JS and WK. Drafting the article or revising it critically for important intellectual content: $E R$, RAM, MMH, RS, SO, JS and WK. Final approval of the version to be published: ER, RAM, MMH, RS, SO, JS and WK.

Funding This work was funded by the Baden-Württemberg State Health Office of the District Government of Stuttgart, Germany, as well as the Regional Health Office in Ravensburg, Germany. Further support was provided by the city of Leutkirch, Germany. Phials for blood samples and part of the laboratory testing were supplied by Sarstedt AG \& Co, Nümbrecht, Germany.

\section{Competing interests None.}

Ethics approval Ethical approval was provided by the Research Ethics Committee of the Baden-Württemberg State Medical Council.

Provenance and peer review Not commissioned; externally peer reviewed.

Data sharing statement There is no additional data available.

\section{REFERENCES}

1. Littman AJ, Kristal AR, White E. Effects of physical activity intensity, frequency, and activity type on 10-y weight change in middle-aged men and women. Int J Obes (Lond) 2005;29:524-33.
2. Hill JO, Wyatt HR. Role of physical activity in preventing and treating obesity. J Appl Physiol 2005;99:765-70.

3. Meisinger $\mathrm{C}$, Löwel $\mathrm{H}$, Thorand $\mathrm{B}$, et al. Leisure time physical activity and the risk of type 2 diabetes in men and women from the general population. The MONICA/KORA Augsburg Cohort Study. Diabetologia 2005:48:27-34.

4. Hu G, Sarti C, Jousilahti P, et al. Leisure time, occupational, and commuting physical activity and the risk of stroke. Stroke 2005:36:1994-9.

5. Hu G, Tuomilehto J, Silventoinen $\mathrm{K}$, et al. The effects of physical activity and body mass index on cardiovascular, cancer and all-cause mortality among 47212 middle-aged Finnish men and women. Int $J$ Obes (Lond) 2005;29:894-902.

6. Schaller N, Seiler H, Himmerich S, et al. Estimated physical activity in Bavaria, Germany, and its implications for obesity risk: results from the BVS-II Study. Int J Behav Nutr Phys Act 2005;2:6.

7. Lampert T, Mensink GBM, Ziese T. Sport and health among adults in Germany. Bundesgesundheitsblatt Gesundheitsforschung Gesundheitsschutz 2005;48:1357-64.

8. Rütten A, Abu-Omar K, Lampert T, et al. Körperliche Aktivität. Gesundheitsberichterstattung des Bundes. Berlin: Robert Koch Institut, 2005;26:7-13.

9. Meisinger $\mathrm{C}$, Löwel H, Heier M, et al. Association of sports activities in leisure time and incident myocardial infarction in middle-aged men and women from the general population: the MONICA/KORA Augsburg cohort study. Eur J Cardiovasc Prev Rehabil 2007;14:788-92.

10. Dowda $\mathrm{M}$, Ainsworth $\mathrm{BE}$, Addy $\mathrm{CL}$, et al. Correlates of physical activity among U.S. young adults, 18 to 30 years of age, from NHANES III. Ann Behav Med 2003;26:15-23.

11. Kaplan MS, Newsom JT, McFarland BH, et al. Demographic and psychosocial correlates of physical activity in late life. Am J Prev Med 2001;21:306-12.

12. Pitsavos C, Panagiotakos DB, Lentzas $\mathrm{Y}$, et al. Epidemiology of leisure-time physical activity in socio-demographic, lifestyle and psychological characteristics of men and women in Greece: the ATTICA Study. BMC Public Health 2005;5:37.

13. Park SY, Murphy SP, Wilkens LR, et al. Dietary patterns using the Food Guide Pyramid groups are associated with sociodemographic and lifestyle factors: the multiethnic cohort study. J Nutr 2005; 135:843-9.

14. Haenle MM, Brockmann SO, Kron M, et al. Overweight, physica activity, tobacco and alcohol consumption in a cross-sectional random sample of German adults. BMC Public Health 2006;6:233.

15. Imhof A, Woodward M, Doering A, et al. Overall alcohol intake, beer, wine, and systemic markers of inflammation in western Europe: results from three MONICA samples (Augsburg, Glasgow, Lille). Eur Heart J 2004;25:2092-100.

16. Voorrips LE, Ravelli AC, Dongelmans PC, et al. A physical activity questionnaire for the elderly. Med Sci Sports Exerc 1991;23:974-9.

17. WHO. Physical status: the use and interpretation of anthropometry. Report of a WHO Expert Committee. World Health Organ Tech Rep Ser 1995;854:427-37.

18. Friedewald WT, Levy RI, Fredrickson DS. Estimation of the concentration of low-density lipoprotein cholesterol in plasma, without use of the preparative ultracentrifuge. Clin Chem 1972;18:499-502.

19. Boehm BO, Claudi-Boehm S, Yildirim S, et al. Prevalence of the metabolic syndrome in southwest Germany. Scand J Clin Lab Invest Suppl 2005;240:122-8

20. Saverymuttu SH, Joseph AE, Maxwell JD. Ultrasound scanning in the detection of hepatic fibrosis and Steatosis. Br Med J (Clin Res Ed) 1986;292:13-15.

21. Sternfeld B, Ainsworth BE, Quesenberry CP. Physical activity patterns in a diverse population of women. Prev Med 1999;28:313-23.

22. Gal DL, Santos AC, Barros H. Leisure-time versus full-day energy expenditure: a cross-sectional study of sedentarism in a Portuguese urban population. BMC Public Health 2005;5:16.

23. Martínez-González MA, Varo JJ, Santos JL, et al. Prevalence of physical activity during leisure time in the European Union. Med Sci Sports Exerc 2001;33:1142-6.

24. Azevedo MR, Araújo CL, Reichert FF, et al. Gender differences in leisure-time physical activity. Int $J$ Public Health 2007;52:8-15.

25. Jurj AL, Wen W, Gao YT, et al. Patterns and correlates of physical activity: a cross-sectional study in urban Chinese women. BMC Public Health 2007;7:213.

26. Chen YJ, Huang YH, Lu FH, et al. The correlates of leisure time physical activity among an adults population from southern Taiwan. BMC Public Health 2011:11:427.

27. Lacour JR, Kostka T, Bonnefoy M. Physical activity to delay the effects of aging on mobility. Presse Med 2002;31:1185-92. 
28. Drygas W, Kwasniewska M, Kaleta D, et al. Epidemiology of physical inactivity in Poland: prevalence and determinants in a former communist country in socioeconomic transition. Public health 2009:123:592-7.

29. Aadahl M, Kjaer M, Jørgensen T. Associations between overall physical activity level and cardiovascular risk factors in an adult population. Eur J Epidemiol 2007;22:369-78.

30. Ball K, Owen N, Salmon J, et al. Associations of physical activity with body weight and fat in men and women. Int $\mathrm{J}$ Obes Relat Metab Disord 2001;25:914-19.

31. Hu G, Qiao Q, Silventoinen K, et al. Occupational, commuting, and leisure-time physical activity in relation to risk for Type 2 diabetes in middle-aged Finnish men and women. Diabetologia 2003;46:322-9.

32. Hu FB, Li TY, Colditz GA, et al. Television watching and other sedentary behaviors in relation to risk of obesity and type 2 diabetes mellitus in women. JAMA 2003;289:1785-91.

33. Hu FB, Leitzmann MF, Stampfer MJ, et al. Physical activity and television watching in relation to risk for type 2 diabetes mellitus in men. Arch Intern Med 2001;161:1542-8.

34. Halldin M, Rosell M, de Faire U, et al. The metabolic syndrome: prevalence and association to leisure-time and work-related physical activity in 60-year-old men and women. Nutr Metab Cardiovasc Dis 2007:17:349-57.

35. Laaksonen DE, Lakka HM, Salonen JT, et al. Low levels of leisuretime physical activity and cardiorespiratory fitness predict development of the metabolic syndrome. Diabetes Care 2002;25:1612-18.
36. Rennie KL, McCarthy N, Yazdgerdi S, et al. Association of the metabolic syndrome with both vigorous and moderate physical activity. Int J Epidemiol 2003;32:600-6.

37. Mendez-Hernandez P, Flores Y, Siani C, et al. Physical activity and risk of metabolic syndrome in an urban Mexican cohort. BMC Public Health 2009;9:276.

38. Hsieh SD, Yoshinaga $\mathrm{H}$, Muto $\mathrm{T}$, et al. Regular physical activity and coronary risk factors in Japanese men. Circulation 1998;97:661-5.

39. Brownson RC, Eyler AA, King AC, et al. Patterns and correlates of physical activity among US women 40 years and older. Am J Public Health 2000;90:264-70.

40. Becker S, Huy C, Brinkhoff KP, et al. "Living an active life"- sports, exercise and health in middle-aged and older adults. An empirical database on physical activity, health behavior and lifestyle in the 50- to 70-year-old residential population of Baden-Wuerttemberg. Gesundheitswesen 2007;69:401-7.

41. Pan SY, Cameron C, Desmeules M, et al. Individual, social, environmental, and physical environmental correlates with physical activity among Canadians: a cross-sectional study. BMC Public Health 2009;9:21.

42. Hagströmer M, Troiano RP, Sjöström M, et al. Levels and patterns of objectively assessed physical activity-a comparison between Sweden and the United States. Am J Epidemiol 2010;171:1055-64.

43. Hansen BH, Kolle E, Dyrstad SM, et al. Accelerometer-determined physical activity in adults and older people. Med Sci Sports Exerc 2012;44:266-72. 